\title{
Impact of enzymatic hydrolysis on the crystal structure, and thermal and textural properties of corn starch
}

\author{
Dehai $\mathrm{Li}^{1,2}$ and Ying $\mathrm{Ma}^{1 *}$ \\ ${ }^{1}$ School of Food Science and Engineering, Harbin Institute of Technology, 202 Haihe Road, Harbin 150090, Heilongjiang \\ Province,People's Republic of China. \\ ${ }^{2}$ College of Forestry, Northeast Forestry University, 26 Hexing Road,Harbin 150040, Heilongjiang Province, People's \\ Republic of China.
}

Accepted 25 February, 2011

\begin{abstract}
Corn starch has been widely used in biomaterial industry as one of the raw materials. The properties of starch such as annealing and the different ratio of amylose and amylopectin in different starch limit its application in production. These properties play a vital role in establishing relationships between other starches in structures and functions. Normal corn starches were treated with isoamylase for different hours and the gelatinization phenomena was observed with differential scanning calorimetry (DSC). The parameters of fracturability, cohesiveness, springiness and adhesive force were all detected by textural profiles analysis. After treatment with isoamylase, the content of amylose chains was increased, hardness and springiness of starch were all enhanced, while cohesiveness and adhesive presented an opposite trend. It was the different ratio of amylose and amylopectin that led to changes in physicochemical properties.
\end{abstract}

Key words: Corn starch, crystal structure, thermal properties, textural properties.

\section{INTRODUCTION}

Starch based polymer materials are seen as biodegradeable polymer matrix reinforced with a natural element and are one of the most often investigated biopolymers which started in the late 1980s (Vilaseca et al., 2007). Many literatures have reported on starch based polymer materials (Fringant et al., 1996; Wang et al., 2004; Rosane et al., 2005; Tzankova et al., 2007; Daniele et al., 2009; Canigueral et al., 2009; Jiirgen, 1998). However, the molecule structure of starch is one of the most important problem, which significantly influences the stress and stiffness properties of starch based biodegradable polymer materials. On the other hand, some literatures have reported that starch degrading enzymes have been used to modify the physicochemical properties of polysaccharides to achieve the desired functional

${ }^{*}$ Corresponding author. E-mail: maying@hit.edu.cn. Tel: +086 0451-86282903; Fax: +086 0451-86282906.

Abbreviations: DSC, Differential scanning calorimeter; $\mathbf{T}_{\mathbf{0}}$, melting temperature; $\mathbf{T}_{\mathbf{p}}$, peak temperature; $\mathbf{T}_{\mathbf{c}}$, conclusion temperature; $\Delta \mathbf{H}_{\mathbf{g}}$, gel enthalpy. properties (Kyungsoo and Paul, 1997; Karakatsanis and Liakopoulou, 2000; Ma et al., 2006; Olivia et al., 2010; Hieronim et al., 2005). The most important tool in providing a saccharride with a specific composition is the use of starch hydrolyzing enzymes (Sakina et al., 2009). Starch was hydrolyzed with a-amylase (Lohmar, 1954; Sakina et al., 2009), and hydrochloric acid (Wang et al., 2001), which strongly affected the amylose content, molecular size of amylose and amylopectin. Although Atsuo and John (1996) have reported that isoamylase hydrolysis can affect the structure and molecule of starch, little information have reported starch hydrolysis with isoamylase, and the relationships between hydrolyzed time and properties of corn are not clear. Therefore, the objective of this study is to investigate the effects of hydrolyzed time on crystal structure, and thermal and textural properties of corn starch.

\section{MATERIALS AND METHODS}

Materials

Commercial corn starch was purchased from the Dacheng Ltd., 
Table 1. Changes of amylose content with hydrolyzed time.

\begin{tabular}{lcccccccc}
\hline Time (h) & 0 & 5 & 10 & 20 & 30 & 40 & 50 & 60 \\
\hline AC (\%) & $25.50 \pm 1.09$ & $31.20 \pm 0.79$ & $43.18 \pm 1.67$ & $52.88 \pm 2.98$ & $74.52 \pm 1.74$ & $86.01 \pm 3.48$ & $89.69 \pm 5.71$ & $91.80 \pm 3.81$ \\
\hline
\end{tabular}

AC: Amylose content.

Changchun city, Jilin province, China. Isoamylase $(\geq 3,000,000$ units/ mg protein) from Pseudomonas sp. was purchased from Sigma, Ltd., USA. All other chemicals were purchased locally and they were of analytical grade.

\section{Method of enzymatic hydrolysis}

Corn starch $(3 \mathrm{~g})$ was added to $0.2 \mathrm{M}$, pH 4.0 ammonium acetate and acetic acid buffer $(97 \mathrm{ml})$. The starch dispersions were kept at $98 \pm 2^{\circ} \mathrm{C}$ for $1 \mathrm{~h}$ to give a completely clear solution and cooled at room temperature. Gelatinized starch dispersions were hydrolyzed by isoamylase $\left(1.33 \mathrm{IU} / \mathrm{g}\right.$ starch) in a water bath at $40 \pm 1^{\circ} \mathrm{C}$ for 5 , $10,15,20,25,30,35,40,45,50,55$ and $60 \mathrm{~h}$. The reaction was terminated by heating the solution for $15 \mathrm{~min}$. The hydrolyzed starch samples were neutralized to $\mathrm{pH} 6.5 \sim 7.0$ with $1 \mathrm{~N} \mathrm{NaOH}$ at $60^{\circ} \mathrm{C}$ according to the method of Cheetham and Tao (1997). Then, the solution was collected by centrifugation at $3000 \mathrm{~g}$ for $15 \mathrm{~min}$, and the paste was determined with texture properties by texture analyzer. After texture determination, the remaining paste was dried at $60^{\circ} \mathrm{C}$ for $36 \mathrm{~h}$ to obtain hydrolyzed corn starch.

\section{Determination of amylose}

Amylose in the starch samples was determined according to the colorimetric procedure of Chrastil (1987). This is a colorimetric method utilizing the property of amylose to form an iodine complex, which was measured by spectrophotometer. The parameter was set to $620 \mathrm{~nm}$ because the absorbance value was maximum at this wavelength. The amylose content in the starch samples was determined from the standard amylose graph prepared.

\section{X-ray diffraction determination}

The X-ray patterns and crystallinity (Nara and Komiya, 1983) of hydrolyzed corn starch were obtained with an X-ray diffractometer (Rigaku Co. Ltd., Rint-2000 type, Tokyo, Japan) operated at voltage of $40 \mathrm{kV}$ and current of $30 \mathrm{~mA}$, target was $\mathrm{Cu}$. Hydrolyzed corn starch (ca. $8 \%, \mathrm{w} / \mathrm{w}$, moisture content) were packed tightly into the aluminium sample holder and diffraction data were collected over an diffraction angle $(2 \theta)$ range from 3 to $60^{\circ}$ at $0.02^{\circ}$ step size and with a scanning speed of $8.0 \% \mathrm{~min}$.

\section{Differential scanning calorimetry determination}

Thermal properties of hydrolyzed corn starch (Kim et al., 1997) were analyzed by a Perkin Elmer pyris 6 differential scanning calorimeter (DSC) (Perkin Elmer, USA). A total weight of $4.0 \mathrm{mg}$ hydrolyzed starch samples (dry basis) and distilled water (1:2, w/w) was placed in pre-weighed aluminum sample pans (PE0219-0062). The pans were sealed hermetically to prevent moisture lose and kept overnight. For all DSC runs, a sealed empty aluminum pan was used as reference. The sample was held isothermally at $20^{\circ} \mathrm{C}$ for $1 \mathrm{~min}$ before being heated from 20 to $140^{\circ} \mathrm{C}$ at $10^{\circ} \mathrm{C} / \mathrm{min}$. The onset, peak and conclusion temperatures, and gelatinization enthalpy $\left(\Delta \mathrm{H}_{\mathrm{g}}, \mathrm{J} / \mathrm{g}\right)$ of gelatinization were determined. The peak temperature and the enthalpy $\left(\Delta \mathrm{H}_{\mathrm{g}}, \mathrm{J} / \mathrm{g}\right)$ associated with the hydrolyzed starch melting peak appearing between 40 and $90^{\circ} \mathrm{C}$ were calculated. All the DSC measurements were performed in triplicate and the results were presented as mean values.

\section{Textural properties of corn starch}

A texture analyzer (TA-XT2, Texture Technologies Corp., UK) with a $50 \mathrm{~kg}$ load cell was used to determine the paste texture properties using a two-cycle compression. The analyser was linked to a computer that recorded the data via a software program called Texture Expert Excede Version 1.0 (Stable Micro Systems Software). A two-cycle compression force versus time program was used to compress the samples till $80 \%$ of the original gel thickness returned to the original position and again compressed. And then, the paste were compressed with a 6- $\mathrm{mm}$ probe at pre-test speed of $1.0 \mathrm{~mm} / \mathrm{s}$, test speed and post-test speed of $0.5 \mathrm{~mm} / \mathrm{s}$. Parameters recorded from the test curves were hardness and adhesiveness, cohesiveness and stringiness (Gupta et al., 2007). The texture analyses were repeated 10 times per samples.

\section{Statistical analysis}

All tests were performed at least in triplicate. Variance analysis (ANOVA) and Duncan multiple-range test were performed by the procedure of SAS 8.0 (SAS Institute, Cary, NC, USA).

\section{RESULTS AND DISCUSSION}

\section{Effects of hydrolyzed time on amylose content of corn starch}

The amylose content of corn starch is shown in Table 1. The amylose content of native corn starch was $25.50 \%$, and was $91.80 \%$ when hydrolysis was $60 \mathrm{~h}$. The amylose content increased rapidly within $40 \mathrm{~h}$, and then increased slowly with hydrolyzed time. In the hydrolyzed process, the enzyme got into the internal of the corn starch granule, and broke down the corn starch molecule to linear chain, so the amylose content increased, when all the branched molecule in corn starch granule was broken down, the amylose content continued to increase. Enzyme first hydrolyzed the amorphous regions before attacking the crystalline regions and both amylose and amylopectin were hydrolyzed simultaneously to smaller molecular sizes. This is similar to the report of Wang and Wang (2001). Gao and Yang (1993) reported that hydrolyzed process could increase the amylose content of potato in the first hours and then changed slowly. From the earlier results, the optimum hydrolyzed time for corn starch was $40 \mathrm{~h}$, which got the highest amylose content. 


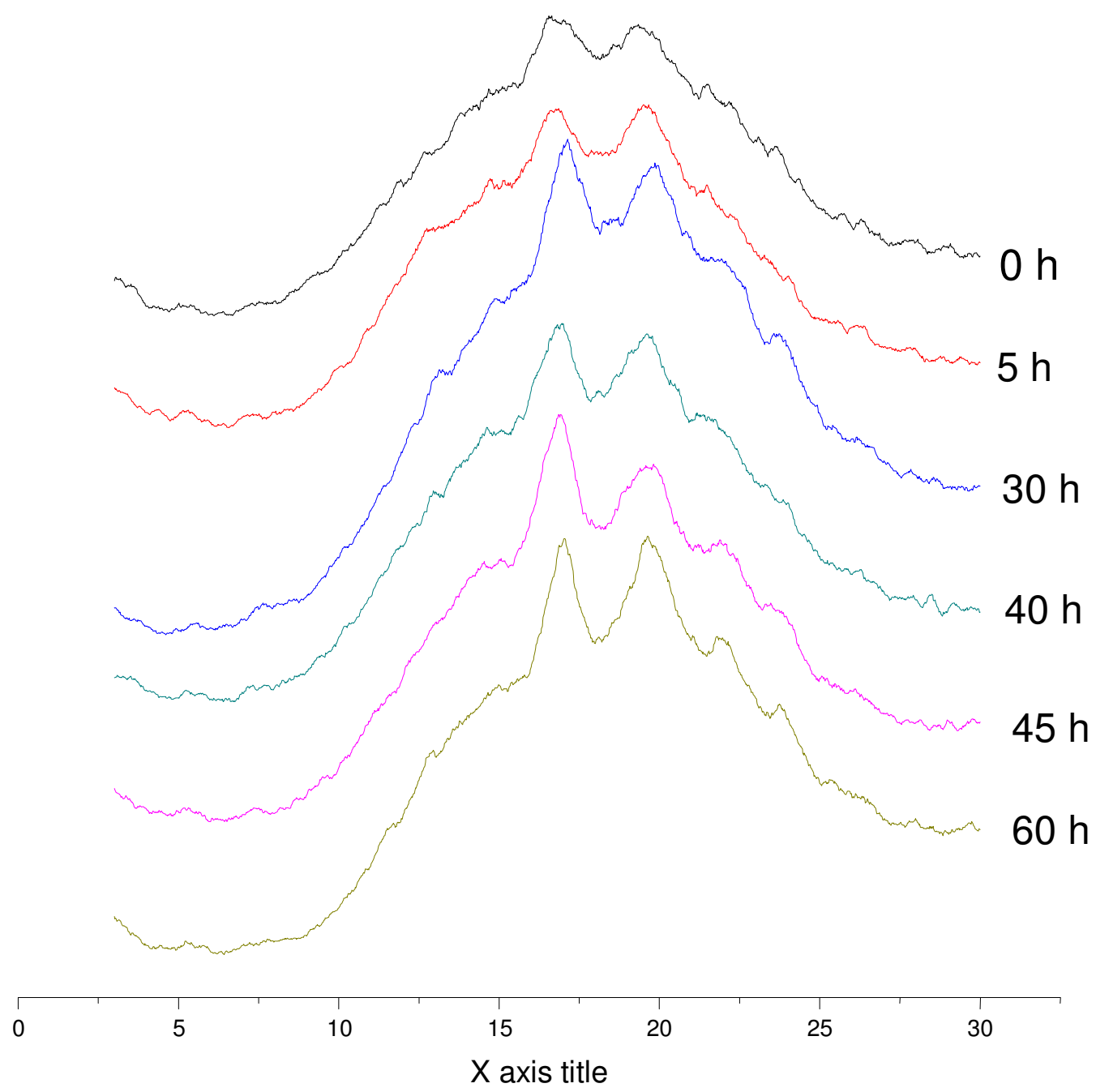

Figure 1. Crystallinity characteristics of hydrolyzed corn starch.

Table 2. Changes of crystallinity degree with hydrolyzed time.

\begin{tabular}{ccccccccc}
\hline Time (h) & 0 & 5 & 10 & 20 & 30 & 40 & 50 & 60 \\
\hline CD (\%) & 23.56 & 22.20 & 19.18 & 17.88 & 16.52 & 12.01 & 10.69 & 9.80 \\
\hline
\end{tabular}

CD: Crystallinity degree.

\section{X-ray analysis of hydrolyzed corn starch}

Figure 1 shows the $\mathrm{X}$-ray patterns of corn starch samples of different hydrolyzed time. Corn starch hydrolyzed for 0 and $5 \mathrm{~h}$, showed an A-type diffraction (Norman et al., 1998), while others cross between A- and V-type patterns (Mua and Jackson, 1997b). Percent crystallinity with different hydrolyzed time was 23.56, 22.20, 19.18, 16.52, $12.01,10.69$ and $9.80 \%$, respectively (Table 2). The crystallinity of corn starch hydrolyzed for $0 \mathrm{~h}$ was the largest, the crystallinity decreased with the hydrolyzed time, hydrolyzed process destroyed the amorphous region in the corn granules, the ratio of crystalline region decreased during hydrolyzed process and the crystallinity degree decreased. This result was in accordance with corn starch of different amylose content (Matveev et al., 2001).

\section{Thermal properties of hydrolyzed corn starch}

Thermal characteristics (Figure 2), as measured by DSC, was observed for corn starch of different hydrolyzed time, respectively. The thermal parameters were also shown in 


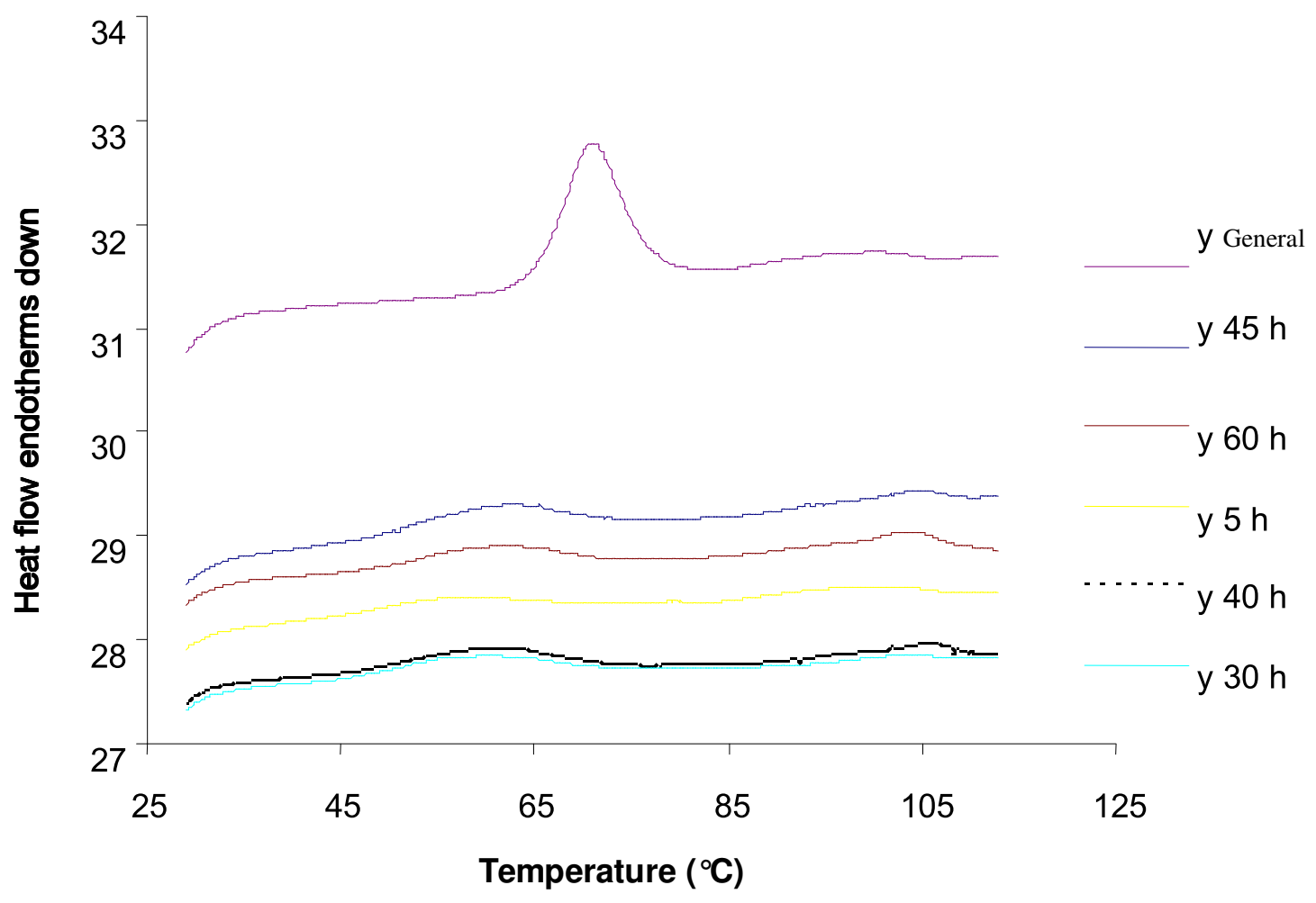

Figure 2. Thermal characteristics of hydrolyzed corn starch determined by DSC.

Table 3. Thermal properties of corn starch with hydrolyzed time.

\begin{tabular}{lcccc}
\hline \multirow{2}{*}{$\begin{array}{c}\text { Hydrolysis time } \\
\text { (h) }\end{array}$} & $\mathbf{T}_{\mathrm{o}}\left({ }^{\circ} \mathbf{C}\right)$ & $\mathbf{T}_{\mathbf{p}}\left({ }^{\circ} \mathbf{C}\right)$ & $\mathbf{T}_{\mathrm{c}}\left({ }^{\circ} \mathbf{C}\right)$ & $\Delta \mathbf{H}_{\mathbf{g}}(\mathbf{J} / \mathbf{g})$ \\
\cline { 2 - 5 } & $67.44 \pm 0.10^{\mathrm{a}}$ & $72.43 \pm 0.13^{\mathrm{a}}$ & $80.75 \pm 0.43^{\mathrm{a}}$ & $17.09 \pm 0.24^{\mathrm{a}}$ \\
5 & $65.09 \pm 0.37^{\mathrm{b}}$ & $70.59 \pm 0.34^{\mathrm{b}}$ & $76.81 \pm 0.09^{\mathrm{b}}$ & $12.94 \pm 0.82^{\mathrm{b}}$ \\
10 & $48.61 \pm 0.37^{\mathrm{c}}$ & $61.66 \pm 0.34^{\mathrm{c}}$ & $71.64 \pm 0.42^{\mathrm{c}}$ & $6.44 \pm 0.66^{\mathrm{c}}$ \\
20 & $46.90 \pm 0.20^{\mathrm{d}}$ & $57.96 \pm 0.61^{\mathrm{d}}$ & $70.87 \pm 0.32^{\mathrm{c}}$ & $5.97 \pm 0.35^{\mathrm{d}}$ \\
30 & $46.78 \pm 0.60^{\mathrm{d}}$ & $57.16 \pm 0.20^{\mathrm{d}}$ & $70.25 \pm 0.32^{\mathrm{c}}$ & $4.97 \pm 0.65^{\mathrm{e}}$ \\
40 & $46.49 \pm 0.58^{\mathrm{d}}$ & $57.06 \pm 0.25^{\mathrm{d}}$ & $70.99 \pm 0.62^{\mathrm{c}}$ & $4.77 \pm 0.46^{\mathrm{d}}$ \\
50 & $46.46 \pm 0.86^{\mathrm{d}}$ & $57.56 \pm 0.65^{\mathrm{d}}$ & $71.03 \pm 0.64^{\mathrm{c}}$ & $4.69 \pm 0.20^{\mathrm{g}}$ \\
60 & $46.31 \pm 0.53^{\mathrm{d}}$ & $57.31 \pm 0.39^{\mathrm{d}}$ & $69.96 \pm 0.90^{\mathrm{c}}$ & $4.55 \pm 0.71^{\mathrm{g}, \mathrm{h}}$ \\
\hline
\end{tabular}

${ }^{a \sim h}$ Means in the same column not followed by the same lowercase superscript letter are significantly different $(p<0.05)$. $T_{0}=$ onset temperature; $T_{p}=$ peak temperature; $T_{c}=$ conclusion temperature; $\Delta H_{g}=$ gelatinization enthalpy.

Table 3. The melting temperature $\left(T_{0}\right)$, peak temperature $\left(T_{p}\right)$, conclusion temperature $\left(T_{c}\right)$ and gel enthalpy $\left(\Delta H_{g}\right)$ decreased with hydrolyzed time increase within $30 \mathrm{~h}$, and then changed slowly. Enzyme first hydrolyzed the amorphous regions before attacking the crystalline regions and both amylose and amylopectin were hydrolyzed simultaneously to smaller molecular sizes. Small starch molecule is very easy to gelatinize, and there maybe some big molecule, therefore, the $T_{0}, T_{p}, T_{c}$ and $\Delta \mathrm{H}_{\mathrm{g}}$ decreased with hydrolyzed time. When the hydrolyzed process finished, the smaller molecular sizes (amylose) reached the highest ratio, the $T_{0}, T_{p}, T_{c}$ and $\Delta \mathrm{H}_{\mathrm{g}}$ changed slowly. Gao and Yang (1993) reported the same results when they hydrolyzed potato starch by isoamylase.

\section{Textural properties of hydrolyzed corn starch}

The textural parameters of corn starch paste are shown in Table 4. Hardness increased from 15.15 to $26.45 \mathrm{~N}$ with hydrolyzed time increase from 0 to $60 \mathrm{~h}$. The 
Table 4. Textural properties of corn starch with different hydrolysis time.

\begin{tabular}{lcccc}
\hline Time (h) & Hardness $(\mathbf{N})$ & Cohesiveness & Stringiness & Adhesive force(N) \\
\hline 0 & $15.15 \pm 0.97$ & $-12.19 \pm 0.39$ & $464.25 \pm 20.31$ & $71.10 \pm 2.59$ \\
5 & $20.13 \pm 1.04$ & $-15.95 \pm 1.03$ & $488.38 \pm 16.98$ & $63.43 \pm 4.81$ \\
10 & $21.81 \pm 0.59$ & $-15.99 \pm 1.61$ & $486.87 \pm 32.64$ & $60.52 \pm 7.25$ \\
20 & $22.65 \pm 2.13$ & $-15.95 \pm 0.29$ & $490.23 \pm 20.65$ & $58.76 \pm 5.36$ \\
30 & $23.16 \pm 1.36$ & $-14.67 \pm 0.96$ & $488.44 \pm 40.15$ & $57.20 \pm 8.01$ \\
40 & $26.32 \pm 1.69$ & $-15.10 \pm 2.31$ & $532.67 \pm 39.51$ & $56.68 \pm 3.54$ \\
50 & $26.88 \pm 2.02$ & $-15.67 \pm 1.54$ & $480.90 \pm 59.01$ & $55.10 \pm 6.20$ \\
60 & $26.45 \pm 1.67$ & $-15.84 \pm 0.36$ & $464.36 \pm 19.28$ & $55.60 \pm 4.35$ \\
\hline
\end{tabular}

hardness increased within $40 \mathrm{~h}$, and then changed slowly. Adhesive force decreased from 71.10 to 55.60 with hydrolyzed time increased from 0 to $60 \mathrm{~h}$. The hardness increased and adhesiveness decrease was related to amylose retrogradation, because small starch molecule in the gel paste retrograded rapidly during the cooling process (Mua and Jackson, 1997a), which contributed to the hardness and adhesiveness changes. The cohesiveness and stringiness value had little changes during hydrolysis process, and the molecule structure had not significant effect on cohesiveness and stringiness.

\section{Conclusions}

Starch from different hydrolyzed time exhibited different physico-chemical properties after isoamylase treatment and their inherent molecular structures before modification played a very important role in determining the functions. Enzyme treatment first hydrolyzed the amorphous regions before attacking the crystalline regions and both amylose and amylopectin were hydrolyzed simultaneously to smaller molecular sizes. Starch gelation was strongly affected by its amylose content, molecular size of amylose and amylopectin, and short and long branch chains in amylopectin. Starch consisting of amylose with a larger molecular size and amylopectin with a larger amount of long branch chain would produce firmer gels. More work is needed to further probe the reaction pattern of enzymatic hydrolysis towards starch from different origins.

\section{ACKNOWLEDGEMENT}

This study was supported by the Critical Project of Heilongjiang Province, China, under the contact No. GA06B401-4.

\section{REFERENCES}

Atsuo K, John F (1996). Reaction of enzymes with starch granules: reaction of isoamylase with native and gelatinized granules. Carbohydr. Res. 287(2): 255-261
Canigueral N, Vilaseca F, Méndez JA, López JP, Barberà L, Puig J, Pèlach MA, Mutjé $P$ (2009). Behavior of biocomposite materials from flax strands and starch-based biopolymer. Chem. Eng. Sci. 64(11): 2651-2658

Cheetham NWH, Tao LP (1997). The effects of amylose content on the molecular size of amylose, and on the distribution of amylopectin chain length in maize starches. Carbohydr. Polymers, 33(4): 251-261

Chrastil J (1987). Improved colorimetric determination of amylose in starches and flours. Carbohydr. Res. 159(1): 154-158.

Daniele CB, Anastacia EFS, MonicaL VJ (2009). Hydrophobic corn starch thermoplastic films produced by plasma treatment Ultramicroscopy, 109(8): 1089-1093.

Fringant C, Desvrieres J, Rinaudo M (1996). Physical properties of acetylated starch-based materials: relation with their molecular characteristics. Polymer, 37(13): 2663-2673.

Gao QY, Yang YG (1993).The improvement of starch film with isoamylase. Food Sci. 165(9): 8-12.

Gupta PK, Sharma A, Sharma R (2007). Textural profile analysis of sunflower-sesame kernel confection (Chikki). J. Texture Stud. 38: 153-165

Hieronim S, Mariusz K, Maciej GL, Leszek K, Bogusaaw W (2005). New biodegradable material based on RF plasma modified starch. Surface Coatings Technol. 200(3): 539-543.

Jiirgen L (1998). Properties and applications of compostable starchbased plastic material. Polymer Degradarion Stability, 59(1): 245-249.

Karakatsanis A, Liakopoulou M (2000). Study of PEG \pm substrate biphasic systems for the enzymatic hydrolysis of gelatinised crude corn starch. J. Food Eng. 46(4): 251-255.

Kim JO, Kim WS, Shin MS (1997). A comparative study on retrogradation of rice starch gels by DSC, X-ray and a-amylase methods. Starch/Stärke. 49(2): 71-75.

Kyungsoo W, Paul AS (1997). Cross-linking of wheat starch and hydroxypropylated wheat starch in alkaline slurry with sodium trimetaphosphate. Carbohydr. Polymers, 33(4): 263-271.

Lohmar RL (1954). The Structure of a-Amylase Modified Waxy-Corn Starchl. Northern Utilization Res. Branch, 76(9): 4608-4611.

Ma Y, Cai CG, Wang J, Sun DW (2006). Enzymatic hydrolysis of corn starch for producing fat mimetics. J. Food Eng. 73(3): 297-303.

Matveev YI, Van SJJG, Nieman C (2001). The relationship between thermodynamic and structural properties of low and high amylose maize starches. Carbohydr. Polymers, 44(2): 151-160.

Mua JP, Jackson DS (1997b). Fine structure of corn amylose and amylopectin fractions with various molecular weights. J. Agric. Food Chem. 45(10): 3840-3847.

Mua JP, Jackson DS (1997a). Relationships between functional attributes and molecular structures of amylose and amylopectin fractions from corn starch. J. Agric. Food Chem. 45(10): 3848-3854.

Nara S, Komiya T (1983). Studies on the relationship between watersaturated state and crystallinity by the diffraction method for moistened potato. Starch/Stärke, 35(12): 407-410.

Norman WH, Cheetham NWH, Tao LP (1998). Variation in crystalline type with amylose content in maize starch granules: an X-ray powder diffraction study Thermal Properties of hydrolysis Corn starch. Carbohydr. Polymers, 36(4): 277-284.

Olivia VL, Noemí EZ, María AG (2010). Physicochemical characteriza- 
tion of chemically modified corn starches related to rheological behavior, retrogradation and film forming capacity. J. Food Eng. 100(1): 160-168.

Rosane MD,Fernanda F,Scremin VS (2005). Thermal Stability of Biodegradable Films Based on Soy Protein and Corn Starch. Macromolecular Symposia, 229(1): 258-265.

Sakina K, Sreerama YN, Raghavendra D,Bhattacharya S,Bhat KK (2009). Properties of enzyme modified corn, rice and tapioca starches. Food Res. Int. 42(10): 1426-1433.

Tzankova DN, Mantia FP (2007). Durability of a starch-based biodegradable polymer. Polymer Degradation Stability, 92(4): 630634.
Vilaseca F, Mendez JA, Pèlach A (2007). Composite materials derived from biodegradable starch polymer and jute strands. Process Biochem. 42(3): 329-334.

Wang LF, Wang, YJ (2001). Structures and physicochemical properties of acid-thinned corn, Potato and Rice Starches. Starch/Starke. 53(11): 570-576.

Wang XL, Yang KK, Wang YZ, Wang DY, Yang Z (2004). Crystallization and morphology of a novel biodegradable polymer system:poly $(1,4-$ dioxan-2-one)/starch blends. Acta Materialia, 52(16): 4899-4905. 